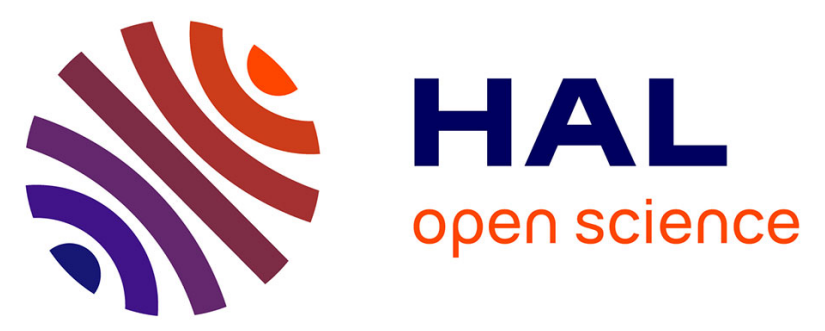

\title{
Invariance of head-pelvis alignment and compensatory mechanisms for asymptomatic adults older than 49 years
}

Celia Amabile, Jean-Charles Le Huec, Wafa Skalli

\section{- To cite this version:}

Celia Amabile, Jean-Charles Le Huec, Wafa Skalli. Invariance of head-pelvis alignment and compensatory mechanisms for asymptomatic adults older than 49 years. European Spine Journal, 2018, 27 (2), pp.458-466. 10.1007/s00586-016-4830-8 . hal-02460531

\section{HAL Id: hal-02460531 \\ https://hal.science/hal-02460531}

Submitted on 30 Jan 2020

HAL is a multi-disciplinary open access archive for the deposit and dissemination of scientific research documents, whether they are published or not. The documents may come from teaching and research institutions in France or abroad, or from public or private research centers.
L'archive ouverte pluridisciplinaire HAL, est destinée au dépôt et à la diffusion de documents scientifiques de niveau recherche, publiés ou non, émanant des établissements d'enseignement et de recherche français ou étrangers, des laboratoires publics ou privés. 


\title{
Invariance of head-pelvis alignment and compensatory mechanisms for asymptomatic adults older than 49 years
}

\author{
Celia Amabile ${ }^{1}$ (1) $\cdot$ Jean-Charles Le Huec $^{2} \cdot$ Wafa Skalli $^{1}$
}

\begin{abstract}
Purpose The aim was to quantify the postural alignment of asymptomatic elderly, in comparison to a reference population, searching for possible invariants and compensatory mechanisms.

Methods 41 volunteers (49-76 years old) underwent biplanar X-rays with 3D reconstructions of the spine and pelvis. Alignment parameters were compared with those of a reference group of asymptomatic subjects younger than 40 years old, with a particular focus on center of acoustic meati (CAM) and odontoid (OD) with regard to hip axis (HA). Possible markers of compensation were also investigated.

Results No significant difference among groups appeared for CAM-HA and OD-HA parameters. Twenty four percent of elders had an abnormally high SVA value and twenty seven percent had an abnormal global spine inclination. Increased pelvic tilt and cervical lordosis allowed maintaining the head above the pelvis.

Conclusions CAM-HA and OD-HA appeared quasi-invariant even in asymptomatic elderly. Some subjects exhibited alteration of spine alignment, compensated at the pelvis and cervical regions.
\end{abstract}

Keywords Postural alignment - 3D reconstruction Asymptomatic elderly

\section{Introduction}

In posture and balance analysis, the head is of primary importance as major receptors, such as eyes and inner ear, are located in the head. Its mass of $4-5 \mathrm{~kg}$ [1] is supported by a flexible rod, the cervical spine, followed by the thoraco-lumbar construct. The last segment of the upper body is the pelvis supporting the upper body weight. Alignment of these three segments needs to be reached to provide an economic balance [2]. However, inclusion of the head segment in radiographic analyses is not yet the standard of care, probably due to the size of the X-ray cassettes. Recent development of head to feet low-dose bi-planar X-rays system permitted visualization of the head segment for postural alignment studies [3]. A recent study reported the relative position of the head with respect of the pelvis by introducing the center of acoustic meati point (CAM), the upper extremity of $\mathrm{C} 2$ dentiform apophyse (OD), and the center of hip axis (HA) [4]. Angles with the vertical, of both lines joining CAM to HA (CAM-HA) and OD to HA (OD-HA), were found invariant, confirming the intuitive alignment of the head above the pelvis for asymptomatic adults younger than 40 years old [4]. With aging, various spine disorders may appear with an impact on spinal alignment and global balance. Alignment of the thorax has widely been investigated on patients, with various parameters, such as the sagittal vertical axis (SVA) and the ratio of $\mathrm{C} 7$ plumbline, over the sacro-femoral distance [5]. In addition, pelvic parameters detailed by Duval-Beaupère allowed for characterization of pelvic morphology (pelvic incidence), retroversion (pelvic tilt), and inclination (sacral slope) [6]. However, aging of asymptomatic subjects is much less investigated [7-11], particularly when including the head. Few studies reported, for asymptomatic adults, alignment 
of the head with the spine and/or pelvis [12-15]. Out of these studies, very few reported the effect of aging on the alignment of the head and the pelvis $[13,15]$. The objective of this study was to describe a group of asymptomatic elderly in comparison to a younger population of asymptomatic adults younger than 40 years old, with a specific focus on investigating the alignment of the head above the pelvis and the compensatory mechanisms recruited to overcome spine alignment alteration.

\section{Materials and methods}

\section{Subjects and data selection}

Volunteers older than 49 years old were extracted from separate studies and were retrospectively included in the study: bi-planar X-rays radiographs were obtained between July 2011 and April 2013 after approval by the Ethics Committee [Comité de Protection des Personnes CPP No. 2010/113 (32 subjects) and CPP No. 06036 (12 subjects)] and written informed consent. Bi-planar X-rays were obtained with the EOS system, a low-dose system permitting the simultaneous head to feet acquisition of sagittal and coronal X-rays [3]. Inclusion criteria were any subject presenting an Oswestry Disability index (ODI) score lower than $20 \%$ [16] and an EVA score (visual analog scale) lower than $2 \%$ in assessing the back pain (including neck pain) [17]. Among exclusion criteria were the presence of low back pain or regular low back pain, lower limbs pathology that could affect the spine, previous surgery on lower limbs, pelvis, or spine. Subjects were asked to stand up in the standardized free standing position, adapted from Faro et al. [18], with hands resting on the mandibles (SRS modified free standing position) and with shifted feet [19]. A medical practitioner familiar to EOS radiographs and not involved in the study blindly reviewed all subjects' radiographs to label and rejected radiographs of subjects with incorrect posture ( 3 on 44). A total of 41 volunteers (24 males and 17 females) with a mean age of 57.9 years (SD 7.9) were included (Table 1).

\section{Imaging data processing}

From bi-planar X-rays, a 3D patient-specific model, including the spine [from $\mathrm{C} 3$ to L5, with addition of the most superior point of dentiform apophyse of C2 (OD)], the pelvis, and the lower limbs was obtained using validated reconstructions techniques [19-22]. In addition, two stereo-corresponding points localizing the acoustic meati were digitized on each reconstruction to compute their center (CAM) [14].

\section{Studied parameters}

All parameters were calculated in the anatomo-gravitational frame [4]. Spinal curvatures (cervical curvature, thoracic kyphosis, and lumbar lordosis) and pelvic parameters (pelvic incidence, pelvic tilt, and sacral slope, overhang S1) were calculated from 3D reconstruction. Were also calculated the sagittal vertical axis (SVA), the T1-pelvic angle, and angles with the vertical of different lines: CAM-HA, OD-HA, C7-HA, and T9-HA.

Spinal inclination was computed as the angle with the vertical of the line that best fits the following anatomical landmarks: middle of the centers of acoustic meati (CAM), the most superior point of dentiform apophyse of C2 (OD), all the vertebral bodies' center from C3 to L5, center of the sacral plate (S1), and middle of the centers of each acetabulum (HA). This method of best fitting line is a robust way to compute the global inclination of the spine. C7PL/SFD, introduced by Barrey et al. [5], is the ratio between the distance $\mathrm{C} 7$ to ${ }^{\text {post-sup }} \mathrm{S} 1$ and the distance HA to ${ }^{\text {post-sup }} \mathrm{S} 1$.

A Lilliefors normality test [23] was run on all parameters. Correlations with age were investigated, using pairwise Spearman correlations (significance level was set at $0.05)$.

\section{Differences between young reference population and elderly}

Comparison was made with a young reference group of 69 asymptomatic volunteers younger than 40 years old [4].
Table 1 Demographic data of the volunteers who participated in the study $(N=41)$, and those of the reference population younger than 40 years old (N=69) [4]

\begin{tabular}{lcclcc}
\hline & \multicolumn{2}{l}{ Elderly $(N=41)$} & & \multicolumn{2}{l}{ Young asymptomatic adults $[4](N=69)$} \\
\cline { 2 - 3 } & Age $(\text { years })^{*}$ & BMI $\left(\mathrm{kg} / \mathrm{m}^{2}\right)$ & & Age $(\text { years })^{*}$ & BMI $\left(\mathrm{kg} / \mathrm{m}^{2}\right)^{*}$ \\
\hline Mean & 57.9 & 25.6 & 26.3 & 22.4 \\
* standard deviation & 7.9 & 4.1 & & 4.7 & 3.1 \\
Min & 49.0 & 18.9 & & 20.1 & 16.6 \\
Max & 76.0 & 39.2 & & 39.7 & 33.2 \\
\hline
\end{tabular}

* Parameter was not found to be drawn from a normal distribution 


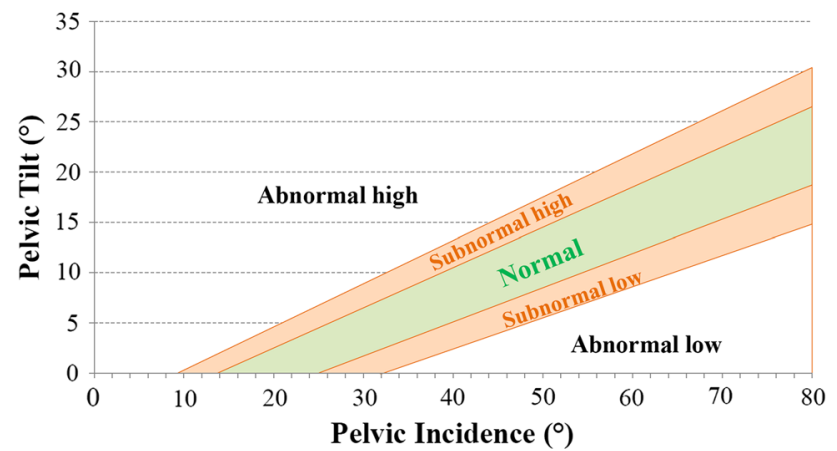

Fig. 1 Normality corridor for the pelvic tilt (PT) based on its relation with pelvic incidence (PI) provided by Vialle et al. [8]: PT $=0.37$ $( \pm 0.03) * \mathrm{PI}-7( \pm 1.5)$

For each parameter, the mean $\mathrm{M}$ and standard deviation SD of the young reference group were used to class elderly as normal if within $\mathrm{M} \pm 1 * \mathrm{SD}$ range, subnormal high between $\mathrm{M}+1 * \mathrm{SD}$ and $\mathrm{M}+2 * \mathrm{SD}$ (low between $\mathrm{M}-1 * \mathrm{SD}$ and $\mathrm{M}-2 * \mathrm{SD}$ ), or abnormal when out of the range $\mathrm{M} \pm 2 * \mathrm{SD}$ (high or low). Pelvic tilt was defined as normal, subnormal, or abnormal depending on the position of the couple of points (pelvic tilt; pelvic incidence) on Fig. 1: the figure was plotted with help of the relation published by Vialle et al. [8].

\section{Spinal alignment alteration}

As the Sagittal Vertical Axis parameter (SVA: posteroanterior distance between $\mathrm{C} 7$ and the most postero-superior point of S1) is widely used to characterize the postural alignment from radiographs, subjects were grouped according to their SVA value when compared with the reference values given by asymptomatic adults younger than 40 years old. Group 1 included subjects with an SVA value identified as normal, subnormal low, or abnormal low. Group 2 included subjects with an SVA value identified as subnormal high or abnormal high.

\section{Compensatory mechanisms}

For those subjects who had abnormal pelvic tilt (value smaller than Mean $-2 * \mathrm{SD}$ or larger than Mean $+2 *$ $\mathrm{SD}$, as defined by the reference population), compensatory mechanisms were investigated with a particular focus on global spinal inclination and cervical lordosis. More specifically, the non-compensated alignment was modeled as explained in Fig. 2: for each of these subjects, the theoretical pelvic tilt was computed from pelvic incidence using the relation provided in [8]. The difference between the measured pelvic tilt and the theoretical one defined the compensation retroversion, then a rotation of the pelvis and spine was performed around the hip axis

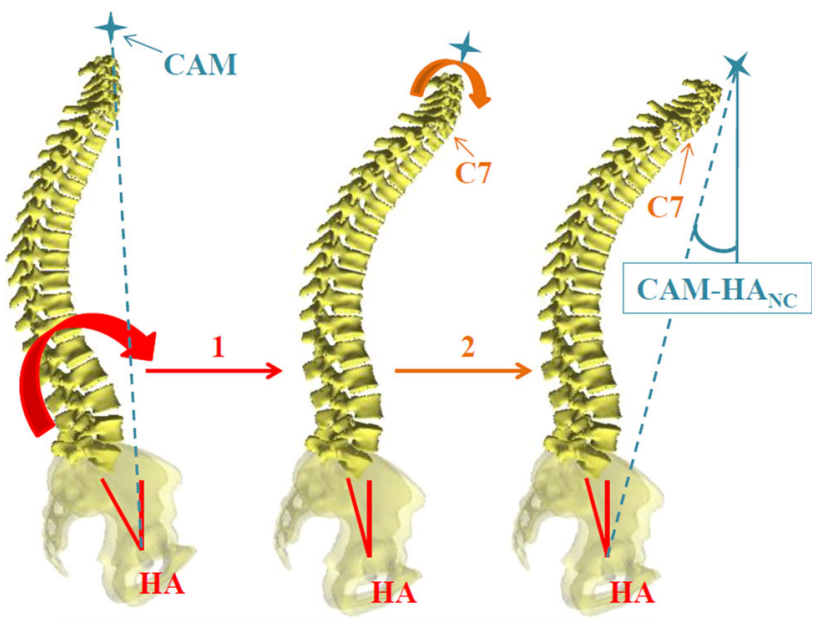

1) Rotation around $\mathrm{HA}$, of pelvis and spine, of alpha $=[$ PT_theoritical - PT_observed $]$

2) Rotation around $\mathrm{C} 7$, of cervical spine, of beta $=\left[\right.$ C3C7_normal $-\mathrm{C} 3 \mathrm{C} 7 \_$observed $]$

CAM-HA $\mathrm{NC}_{\mathrm{N}}$ Newly computed value of CAM-HA, with no compensation

Fig. 2 Schematic representation of the computation of the noncompensated posture represented in Fig. 6. PT_theoretical refers to the theoretical value of PT computed from PI as given by Vialle et al. [8]. C3C7_normal refers to the mean value reported for asymptomatic adults younger than 40 years old which is $6^{\circ}$ [4]. Similar to CAM$\mathrm{HA}_{\mathrm{NC}}$, a newly inclination OD-HA $\mathrm{NC}_{\mathrm{NC}}$ was computed following the same steps

to simulate an alignment without such compensation retroversion. The cervical compensation lordosis was computed as the difference between the measured cervical lordosis to the reference value provided by the asymptomatic adults younger than 40 years old $\left(6^{\circ}\right)$ [4]. A second rotation of the cervical spine around $\mathrm{C} 7$ was then applied to suppress the cervical lordosis compensation. The new simulated alignment, without pelvic retroversion or cervical hyperlordosis, allowed for the computation of a new theoretical non-compensated CAM-HA (respectively, OD-HA), named CAM-HA $\mathrm{NC}$ (resp. OD-HA ${ }_{\mathrm{NC}}$ ) (Fig. 2).

\section{Results}

\section{Sample description}

Over all parameters used to study correlations, only two were found to not be drawn from a normal distribution [CAM-HA $(p=0.04)$ and Age $(p=0)]$. Means and SD were reported for all parameters (Figs. 3, 4). The inclinations with the vertical, of the line joining CAM to HA 


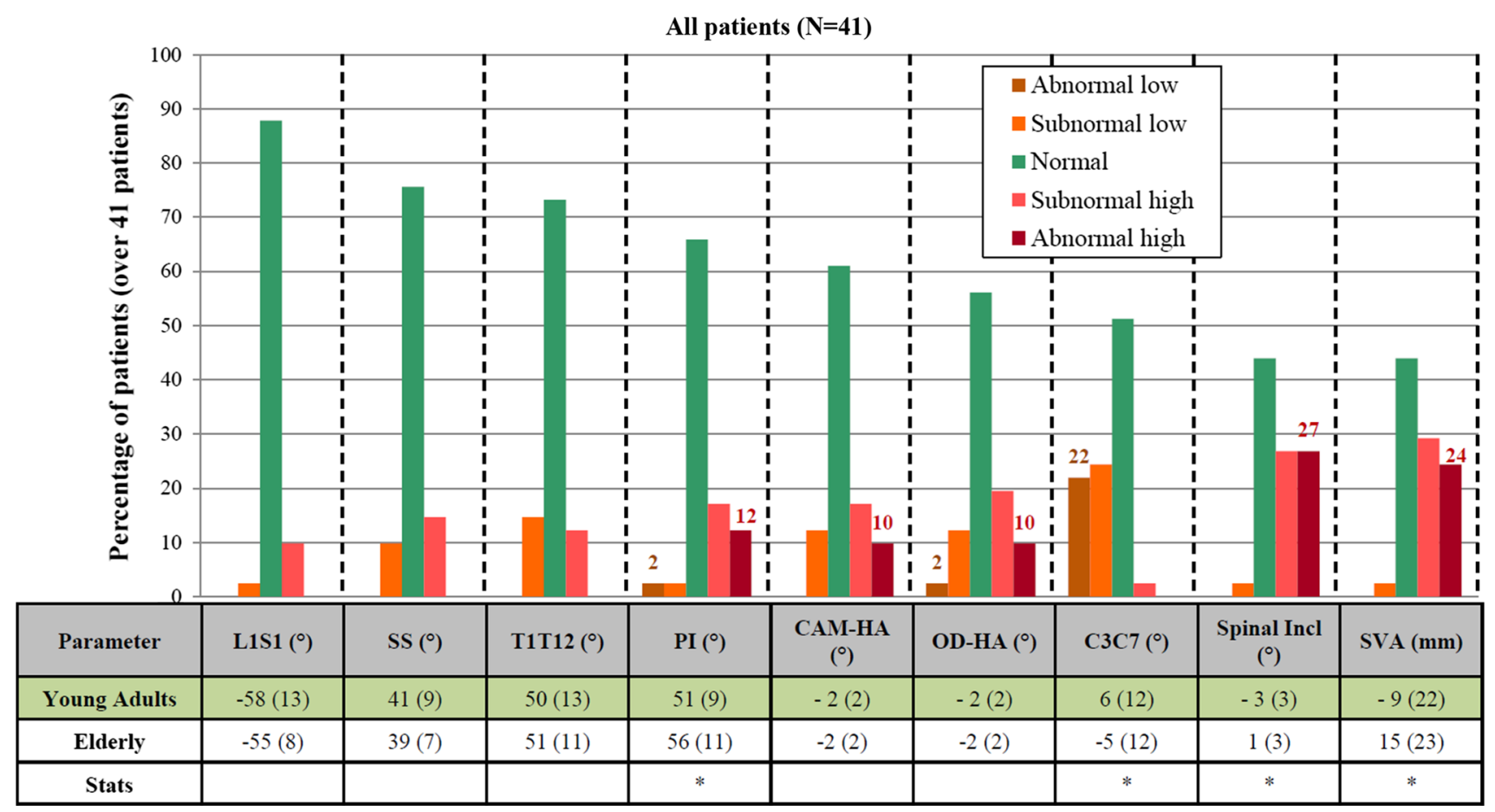

Fig. 3 Distribution of different parameters' values, for elderly, compared with corridors given by the young Group [4]: percentage of subjects is computed as the percentage over the whole population $(N=41)$. T1T12 is the thoracic kyphosis, L1S1 is the lumbar lordosis, and $\mathrm{C} 3 \mathrm{C} 7$ is the cervical curvature. Means $(1 *$ standard deviation) for Young Group [4] and Elderly Group. *Significant differences were found between both groups

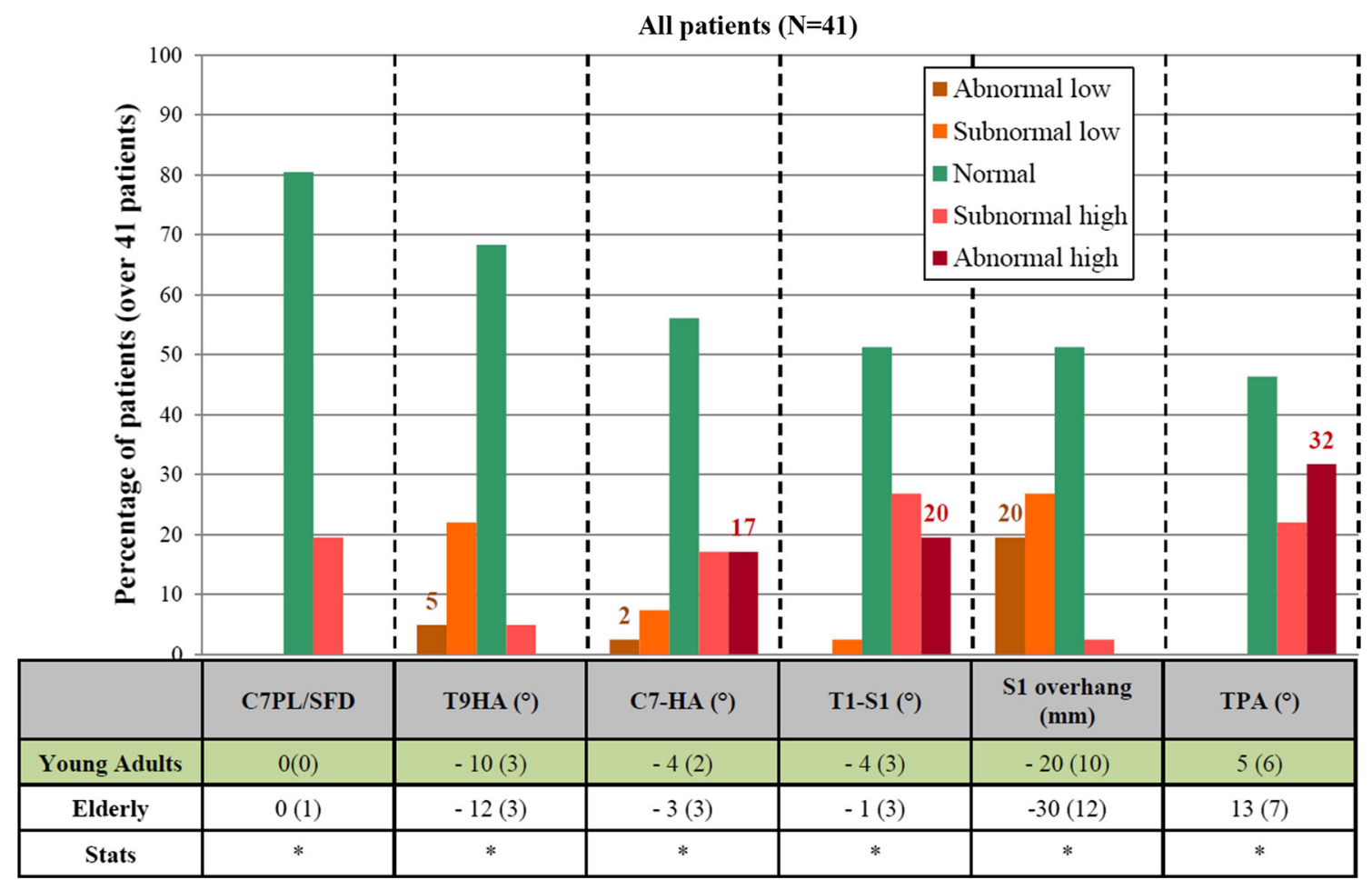

Fig. 4 Distribution of different parameters' values, for elderly, compared with corridors given by the young Group [4]: percentage of subjects is computed as the percentage over the whole population
$(N=41)$. Means $(1 *$ standard deviation) for Young Group [4] and Elderly Group. *Significant differences were found between both groups 

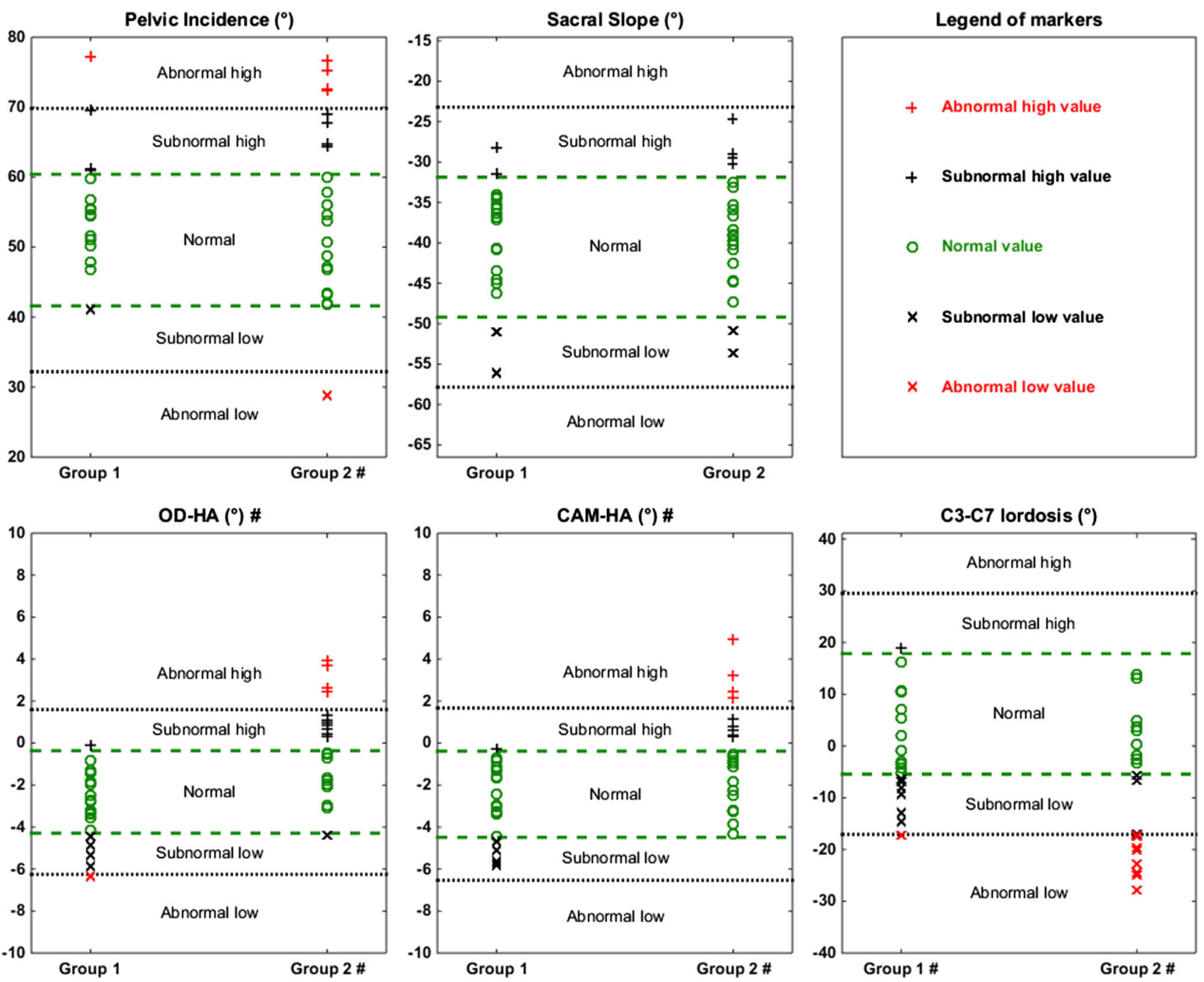

Fig. 5 Repartition of parameters' values for Group $1 \quad(N=19$ subjects with SVA values subnormal low or normal) and Group 2 ( $N=22$ subjects with SVA values subnormal high or abnormal high), compared with intervals (dashed green and black lines) given by

and of the line joining OD to HA, had the lowest variation (SD of $2^{\circ}$ for both) and were the closest to the vertical: mean inclination of $3^{\circ}$ for both. The spinal inclination presented a similar mean $\left(3^{\circ}\right)$ and $\mathrm{SD}\left(2^{\circ}\right)$. In comparison, means (SD) of C7-HA and T9-HA were, respectively, of $4^{\circ}\left(2^{\circ}\right)$ and $12^{\circ}\left(3^{\circ}\right)$. Following the different types of alignment defined by Roussouly [24], $27 \%$ of the elderly presented a type 1 or 2 alignment, $59 \%$ presented a type 3 alignment, and $15 \%$ presented a type 4 alignment.

Parameters significantly correlated with age with $R>0.3$, are: sagittal vertical axis $(R=0.48)$, spinal inclination $(R=0.46)$, T1-pelvic angle $(R=0.44)$, pelvic tilt $(R=0.35)$, overhang $\mathrm{S} 1(R=-0.35)$, and cervical curvature $(R=-0.42)$. mean (M) and standard deviation (SD) of reference population [4]. \# In the title means a significant difference between Groups 1 and 2 . \# Next to Group 1 (resp. Group 2) means a significant difference with the Young Group

\section{Differences with asymptomatic subjects younger than 40 years old}

Comparison between Elderly and Young groups is presented in Figs. 3 and 4. In the following, Young group (respectively, Elderly group) refers to asymptomatic adults younger than 40 years old (respectively, older than 49 years). No statistical differences were found between groups regarding CAM-HA and OD-HA angles. Significant differences were observed between groups for several parameters (Figs. 3, 4, 5), including (mean values given in the following):

- $\mathrm{C} 3 \mathrm{C} 7$ lordosis: $-5^{\circ}$ for the elderly group vs $6^{\circ}$ for the young group, 
Table 2 Results of statistical tests to assess differences between the Young Group [4], Group 1 ( $N=19$ subjects with SVA values subnormal low or normal) and Group 2 ( $N=22$ subjects with SVA values subnormal high or abnormal high)

\begin{tabular}{|c|c|c|c|c|c|c|}
\hline Parameters & $\begin{array}{l}\mathrm{M}(1 * \mathrm{SD}) \\
\text { Young }\end{array}$ & $\begin{array}{l}\mathrm{M}(1 * \mathrm{SD}) \\
\text { Group } 1\end{array}$ & $\begin{array}{l}\text { Young Group vs } \\
\text { Group } 1\end{array}$ & $\begin{array}{l}\mathrm{M}(1 * \mathrm{SD}) \\
\text { Group } 2\end{array}$ & $\begin{array}{l}\text { Young Group vs } \\
\text { Group } 2\end{array}$ & $\begin{array}{l}\text { Group } 1 \text { vs } \\
\text { Group } 2\end{array}$ \\
\hline Age (years) & $26(5)$ & $57(6)$ & $\sqrt{ }$ & $59(9)$ & $\sqrt{ }$ & \\
\hline BMI $\left(\mathrm{kg} / \mathrm{m}^{2}\right)$ & $22(3)$ & $26(5)$ & $\sqrt{ }$ & $26(3)$ & $\sqrt{ }$ & \\
\hline $\mathrm{PI}\left({ }^{\circ}\right)$ & $51(9)$ & $55(8)$ & & $56(13)$ & $\sqrt{ }$ & \\
\hline $\operatorname{SS}\left({ }^{\circ}\right)$ & $-41(9)$ & $-39(7)$ & & $-39(7)$ & & \\
\hline PT $\left(^{\circ}\right)$ & $11(6)$ & $16(5)$ & $\sqrt{ }$ & $17(10)$ & $\sqrt{ }$ & \\
\hline $\begin{array}{l}\text { Spinal inclination (sagittal } \\
\text { plane) }\left(^{\circ}\right)\end{array}$ & $-3(3)$ & $-2(2)$ & & $3(2)$ & $\sqrt{ }$ & $\sqrt{ }$ \\
\hline OD-HA (sagittal plane) $\left(^{\circ}\right)$ & $-2(2)$ & $-3(2)$ & & $0(2)$ & $\sqrt{ }$ & $\sqrt{ }$ \\
\hline $\begin{array}{l}\text { CAM-HA (sagittal plane) } \\
\left({ }^{\circ}\right)\end{array}$ & $-2(2)$ & $-3(2)$ & & $0(2)$ & $\sqrt{ }$ & $\sqrt{ }$ \\
\hline $\mathrm{C} 3 \mathrm{C} 7$ curvature $\left(^{\circ}\right)$ & $6(12)$ & $-1(10)$ & $\sqrt{ }$ & $-8(13)$ & $\sqrt{ }$ & \\
\hline SVA $(\mathrm{mm})$ & $-9(22)$ & $-5(12)$ & & $32(15)$ & $\sqrt{ }$ & $\sqrt{ }$ \\
\hline
\end{tabular}

$M$ mean, $S D$ standard deviation

- pelvic incidence: $56^{\circ}$ for the elderly group vs $51^{\circ}$ for the young group,

- pelvic tilt: $17^{\circ}$ for the elderly group vs $11^{\circ}$ for the young group,

- SVA: $15 \mathrm{~mm}$ for the elderly group vs $-9 \mathrm{~mm}$ for the young group.

\section{SVA subgroups analysis}

Group $1(N=19)$ included elderly with a normal or subnormal low SVA value. Group $2(N=22)$ included elderly with subnormal high or abnormal high SVA value (Fig. 3). Overall, $44 \%$ of subjects presented a normal spinal inclination and $27 \%$ presented an abnormal high spinal inclination (Fig. 3). Only, $10 \%$ (resp. 12\%) of subjects presented an abnormal (high or low) CAM-HA (resp. ODHA) (Fig. 3). Figure 5 and Table 2 present for each Group 1 and 2, comparison with reference values for: pelvic incidence, sacral slope, pelvic tilt, spinal inclination, ODHA, and CAM-HA.

\section{Compensatory mechanisms}

In groups 1 and 2, elderly presenting an abnormal low cervical lordosis were identified: $5 \%$ in Group 1 and $36 \%$ in Group 2. Elderly presenting an abnormal high or low pelvic tilt (with respect of the classification presented in Fig. 1) were labeled: $16 \%$ in Group 1 and $36 \%$ in Group 2. Elderly presenting an abnormal high spinal inclination were identified: $50 \%$ for Group 2. All these elderly $(N=20)$ were studied in more details. Following the different types of alignment defined by Roussouly [24], $30 \%$ of these 20 elderly presented a type 1 or 2 alignment, $55 \%$ presented a type 3 alignment, and $15 \%$ presented a type 4 alignment.

CAM-HA ${ }_{\mathrm{NC}}$ and OD-HA $\mathrm{NC}_{\mathrm{NC}}$ inclinations were computed for these subjects, without pelvic tilt compensation and without cervical compensation (see Fig. 2). Among these, 13 elderly presented a newly computed abnormal CAM-HA $\mathrm{NC}_{\mathrm{NC}}$ or OD-HA $\mathrm{NC}_{\mathrm{NC}}$ greater than $3^{\circ}$, while their initial value of CAM-HA or OD-HA was in average of $-1^{\circ}\left(\mathrm{SD}\right.$ of $\left.3^{\circ}\right)$. These 13 elderly presented all the different alignment types described by Roussouly [24] in the same proportion as the initial population: $38 \%$ of these 13 elderly presented a type 1 or 2 alignment, $54 \%$ presented a type 3 alignment, and $15 \%$ presented a type 4 alignment.

Overall, these 13 elderly presented a large pelvic retroversion: mean difference real PT with theoretical PT of $8^{\circ}\left(\mathrm{SD} 5^{\circ}\right)$. They also presented a high cervical curvature: mean difference between real $\mathrm{C} 3 \mathrm{C} 7$ lordosis and $6^{\circ}$ (normal $\mathrm{C} 3 \mathrm{C} 7$ curvature): $-19^{\circ}\left(\mathrm{SD} 10^{\circ}\right)$. Influence of the pelvic tilt and cervical curvature in the compensated posture of 3 of these 14 elderly is illustrated in Fig. 6.

\section{Discussion}

Postural alignment of asymptomatic adults older than 49 years old was investigated and compared with reference values from asymptomatic adults younger than 40 years old [4]. Quasi-invariance of the head-position above the pelvis has previously been previously reported in asymptomatic adults younger than 40 years old [4], and was conserved for elderly. This confirms the intuition of clinicians, summarized by the concept of conus of economy described by Dubousset [2]. While both CAM-HA and OD- 

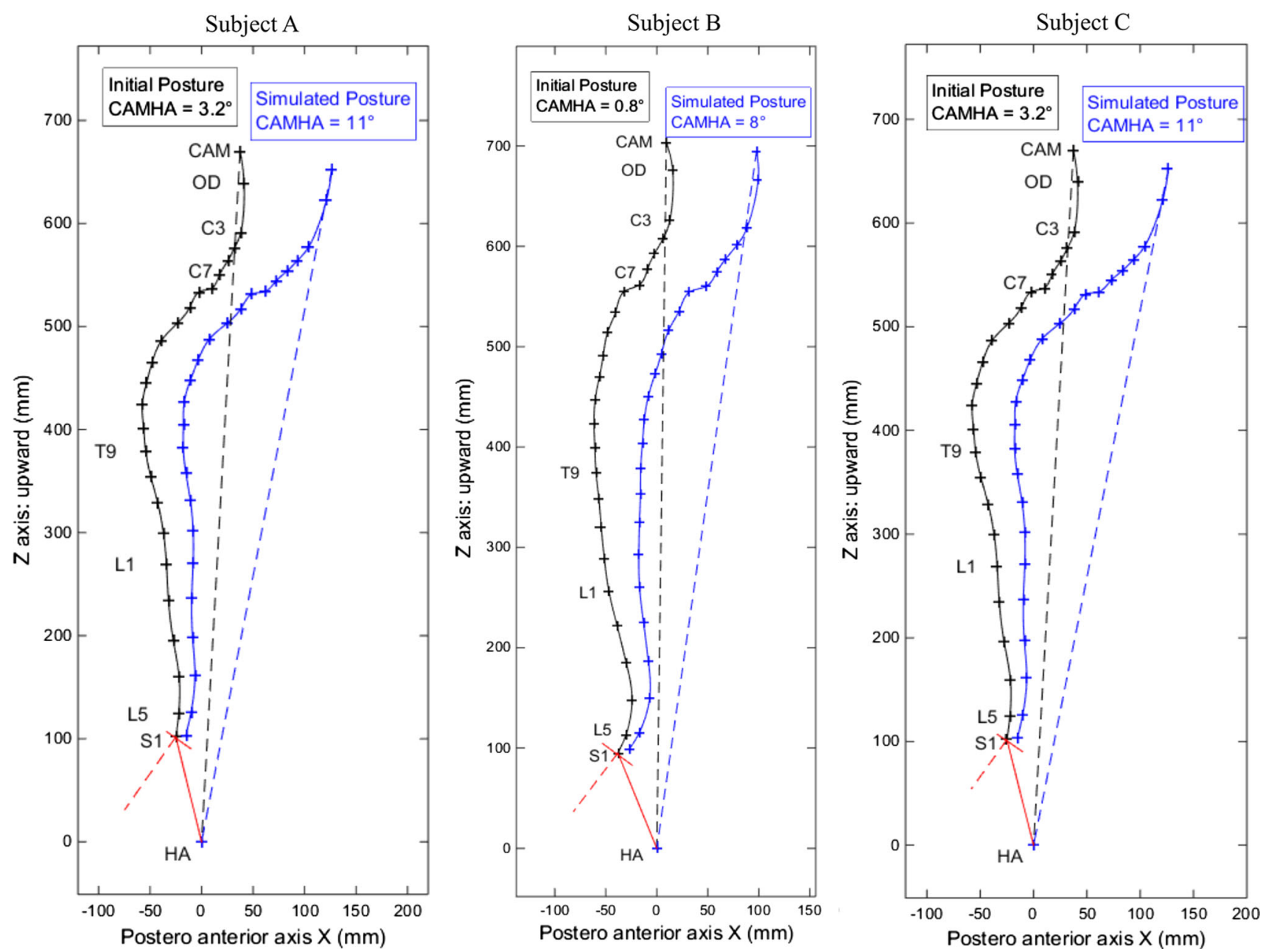

Fig. 6 Initial posture (black curve) and posture simulated without compensation at the pelvic and cervical level (blue curve): theoretical value of the pelvic tilt was computed from the pelvic incidence [8] and cervical curvature was fixed at $6^{\circ}$, as this value was reported as the mean value for asymptomatic adults younger than 40 years old

HA appeared as quasi-invariant on asymptomatic subjects, thus being potential markers of imbalance in subjects with spinal disorders, OD-HA could be of particular interest because of its visibility on most X-rays, while CAM-HA could not be visible for tall people because of the size of the bi-planar X-ray system.

Observation of the elderly was similar to the published studies. They presented a greater T1T12 thoracic kyphosis and a smaller L1S1 lordosis than the asymptomatic adults younger than 40 years old [4]. This loss of lordosis and gain of kyphosis with aging have previously been reported in the literature $[9,11]$.

This study focused on the postural alteration of asymptomatic elderly assessed with different parameters: the Sagittal Vertical Axis, the C7PL/SFD [5], and the spinal inclination. When studying, in detail, the compensatory mechanisms, 13 elderly can be identified with the
[4]. The red lines represent the sacral plate and the link from S1 to HA to account for pelvic incidence. For asymptomatic adults younger than 40 years old, mean value for CAM-HA was $-2^{\circ}$. Subject A (resp. B, resp. C) was an elderly with pelvic incidence higher than $60^{\circ}$ (resp. between $44^{\circ}$ and $60^{\circ}$; resp. lower than $44^{\circ}$ )

head above the pelvis at the expense of an increased pelvic retroversion and increased cervical lordosis. In comparison, 7 subjects were identified as malaligned based on SVA, 10 based on C7PL/SFD [5], and 6 based on the spinal inclination. Although SVA, C7PL/SFD, and spinal inclination are useful in the assessment of specific alterations, classification based on one of these parameters did not identify all the 13 subjects labeled in this study as subjects presenting a compensated posture. The population of elder adults represented the different types of alignment described by Roussouly [24], as did the different subgroups of elders analyzed in this study.

Some of these subjects appeared with maximal compensation, relative to the range of possible compensation. A longitudinal study following-up their postural evolution over time would assess if postural disorders will occur earlier for these subjects compared with the others. This 
would confirm the results of this study in the definition of an early marker of postural alteration.

\section{Limitations and perspectives}

Due to the position in the EOS cabin (shifted feet), the measured parameters of the thigh must be interpreted with precaution. As most of the radiographs did not completely include the lower legs, the analysis of the lower limbs and their role as compensatory mechanisms were excluded from the current study $[25,26]$. Another limitation relates to the constraints associated with the image acquisition in the EOS cabin. While standardized Free Standing Position allowed to be as close as possible to the natural posture, additional observation of routine relaxed posture, out of the cabin, could be interesting in future studies.

In addition, further investigation on a wider range of subjects would be interesting to confirm these results obtained on reasonable sample size (41 elderly) split in two subgroups of around 20 subjects each. Potential bias regarding the subjects' selection was removed as exclusion criteria were similar between both populations, with the addition of clinical scores for the elderly to only recruit asymptomatic elderly. In addition, both groups' data collection and image processing followed the same protocol. Including patients in a future study would be of special interest to assess if a threshold of degree of compensation appears allowing for identification of patients with increased pain or disability. It would also be interesting to test for a special link between severity of the disease (and/or quality of life scores) and lack of compensation.

\section{Conclusion}

Postural alignment of asymptomatic adults older than 49 years was studied. The position of the head above the pelvis appears as quasi-invariant in elderly. Despite the non-pathological condition of the subjects, in nearly $32 \%$ of them, this invariance is maintained at the expense of compensatory mechanisms at the pelvis and cervical level. Future investigation of those compensatory mechanisms, in longitudinal studies, could lead toward early assessment of subjects at risk of postural alteration, possibly leading to spinal disorders impacting quality of life.

Acknowledgments The authors are grateful to the Banque Public d'Investissement for financial support through the dexEOS project part of the French FUI14 program. Authors thank the ParisTech BiomecAM chair program on subject-specific musculoskeletal modeling, and in particular COVEA and Société Générale. The authors thank EOS Imaging for their help in the data collection.

\section{Compliance with ethical standards}

Conflict of interest All authors declare that they have no conflict of interest.

\section{References}

1. Vital J-M, Senegas J (1986) Anatomical bases of the study of the constraints to which the cervical spine is subject in the sagittal plane. A study of the center of gravity of the head. Surg Radiol Anat 8:169-173. doi:10.1007/BF02427845

2. Dubousset J (1994) Three-dimensional analysis of the scoliotic deformity. In: Weinstein SL (ed) Pediatr. spine Princ. Pract., Wein-stei. Raven Press 1td, pp 479-496

3. Dubousset J, Charpak G, Skalli W et al (2010) EOS: a new imaging system with low dose radiation in standing position for spine and bone \& joint disorders. J Musculoskelet Res 13:1-12

4. Amabile $\mathrm{C}$, Pillet $\mathrm{H}$, Lafage $\mathrm{V}$ et al (2016) A new invariant parameter characterizing the postural alignment of young healthy adults. Eur Spine J. doi:10.1007/s00586-016-4552-y

5. Barrey C, Roussouly P, Perrin G, Le Huec J-C (2011) Sagittal balance disorders in severe degenerative spine. Can we identify the compensatory mechanisms? Eur Spine J 20:626-633. doi:10. 1007/s00586-011-1930-3

6. Duval-Beaupère G, Schmidt C, Cosson P (1992) A Barycentremetric study of the sagittal shape of spine and pelvis: the conditions required for an economic standing position. Ann Biomed Eng 20:451-462

7. El Fegoun AB, Schwab F, Gamez L et al (2005) Center of gravity and radiographic posture analysis: a preliminary review of adult volunteers and adult patients affected by scoliosis. Spine (Phila Pa 1976) 30:1535-1540

8. Vialle R, Levassor N, Rillardon L et al (2005) Radiographic analysis of the sagittal alignment and balance of the spine in asymptomatic subjects. J Bone Joint Surg Am 87:260-267. doi:10.2106/JBJS.D.02043

9. Schwab F, Lafage V, Boyce R et al (2006) Gravity line analysis in adult volunteers: age-related correlation with spinal parameters, pelvic parameters, and foot position. Spine (Phila Pa 1976) 31:E959-E967. doi:10.1097/01.brs.0000248126.96737.0f

10. Lafage V, Schwab F, Skalli W et al (2008) Standing balance and sagittal plane spinal deformity: analysis of spinopelvic and gravity line parameters. Spine (Phila Pa 1976) 33:1572-1578

11. Kim YB, Kim YJ, Ahn YJ et al (2014) A comparative analysis of sagittal spinopelvic alignment between young and old men without localized disc degeneration. Eur Spine J 23:1400-1406. doi:10.1007/s00586-014-3236-8

12. Gangnet N, Pomero V, Dumas R et al (2003) Variability of the spine and pelvis location with respect to the gravity line: a threedimensional stereoradiographic study using a force platform. Surg Radiol Anat 25:424-433. doi:10.1007/s00276-003-0154-6

13. Le Huec J-C, Demezon H, Aunoble S (2014) Sagittal parameters of global cervical balance using EOS imaging: normative values from a prospective cohort of asymptomatic volunteers. Eur Spine J 24:63-71. doi:10.1007/s00586-014-3632-0

14. Steffen J-S, Obeid I, Aurouer N et al (2010) 3D postural balance with regard to gravity line: an evaluation in the transversal plane on 93 patients and 23 asymptomatic volunteers. Eur Spine J 19:760-767. doi:10.1007/s00586-009-1249-5

15. Iyer S, Lenke LG, Nemani VM et al (2016) Variations in sagittal alignment parameters based on age: a prospective study of asymptomatic volunteers using full-body radiographs. Spine (Phila Pa 1976). doi:10.1097/BRS.0000000000001642 
16. Fairbank JC, Couper J, Davies JB, O'Brien JP (1980) The Oswestry low back pain disability questionnaire. Physiotherapy 66:271-273

17. Million R, Hall R, Nilsen K, Baker R (1982) Assessment of the progress of the back-pain patient. Spine (Phila $\mathrm{Pa}$ 1976) 7:204-212

18. Faro FD, Marks MC, Pawelek J, Newton PO (2004) Evaluation of a functional position for lateral radiograph acquisition in adolescent idiopathic scoliosis. Spine (Phila Pa 1976) 29:2284-2289. doi:10.1097/01.brs.0000142224.46796.a7

19. Chaibi Y, Cresson T, Aubert B et al (2012) Fast 3D reconstruction of the lower limb using a parametric model and statistical inferences and clinical measurements calculation from biplanar X-rays. Comput Methods Biomech Biomed Engin 15:457-466. doi:10.1080/10255842.2010.540758

20. Mitton D, Deschênes S, Laporte S et al (2006) 3D reconstruction of the pelvis from biplanar radiography. Comput Methods Biomech Biomed Engin 9:1-5

21. Humbert L, De Guise JA, Godbout B et al (2009) Fast 3D reconstruction of the spine from biplanar radiography: a diagnosis tool for routine scoliosis diagnosis and research in biomechanics.
Comput Methods Biomech Biomed Engin 12:151-163. doi:10. 1080/10255840903081222

22. Quijano S, Serrurier A, Aubert B et al (2013) Three-dimensional reconstruction of the lower limb from biplanar calibrated radiographs. Med Eng Phys 35:1703-1712. doi:10.1016/j.medengphy. 2013.07.002

23. Lilliefors HW (1967) On the Kolmogorov-Smirnov test for normality with mean and variance. J Am Stat Assoc 62:399-402

24. Roussouly P, Gollogly S, Berthonnaud E, Dimnet J (2005) Classification of the normal variation in the sagittal alignment of the human lumbar spine and pelvis in the standing position. Spine (Phila Pa 1976) 30:346-353

25. Barrey C, Roussouly P, Le Huec J-C et al (2013) Compensatory mechanisms contributing to keep the sagittal balance of the spine. Eur Spine J 22:S834-S841. doi:10.1007/s00586-013-3030-z

26. Diebo B, Ferrero E, Lafage R et al (2015) Recruitment of compensatory mechanisms in sagittal spinal malalignment is age and regional deformity dependent: a full-standing axis analysis of key radiographical parameters. Spine (Phila Pa 1976) 40:642-649. doi:10.1097/BRS.0000000000000844 